\title{
ANALISIS PERSEPSI KONSUMEN TERHADAP EKUITAS MEREK PRODUK ES KRIM
}

\author{
An Analysis of Consumer's Perceive of Brand Equity of Ice Cream Products \\ FITRAHDINI ${ }^{1}$, UJANG SUMARWAN ${ }^{2}$, RITA NURMALINA ${ }^{3}$ \\ ${ }^{1}$ Marketing Executive PT Barclay Products-The Tempo Group \\ ${ }^{2}$ Staf Pengajar Program MB-IPB dan Departemen Ilmu Keluarga dan Konsumen, Fakultas \\ Ekologi Manusia, Institut Pertanian Bogor, Jalan Lingkar Kampus IPB Dramaga, \\ Bogor 16680 \\ ${ }^{3}$ Staf Pengajar Program MB-IPB dan Departemen Agribisnis, Fakultas Ekonomi dan \\ Manajemen, Institut Pertanian Bogor, Jalan Lingkar Kampus IPB Dramaga, Bogor 16680
}

\begin{abstract}
The brand equity is created not only by some dimensions of brand equity such as brand awareness, brand association, perceived quality, and brand loyalty but also created by marketing activities called antecedents of brand equity. This research used brand equity dimensions as variables. The aim of this research was to analyze consumer's perceive toward brand equity of ice cream (IM Meiji). The data was collected from 150 respondents in Bogor. The data analysis technique was the multicolinearity measurement with Structural Equation Modeling (SEM) assisted by a computer application LISREL (Linear Structural Relationship) 8.3 version. The output analysis of SEM indicated that the structural model could be accepted (close-fit) based on empirical facts. The structural model indicated that the brand equity of ice cream products (IM Meiji) was created by brand association (compound with brand awareness), brand loyalty, and perceived quality. Brand loyalty with significant positive correlation toward brand equity had the biggest contribution, while the perceived quality had the lowest contribution with negative correlation toward brand equity. The estimation of parameter also showed that advertisement and distribution intensity had significant positive correlation towards brand equity, but price had negative correlation.
\end{abstract}

Key words: brand, equity, ice cream, perceive, SEM

\section{PENDAHULUAN}

Industri es krim di Indonesia kini masih terus berpeluang untuk meningkatkan pertumbuhannya karena terdapat terus mengalami peningkatan dalam konsumsi per kapita seiring dengan meningkatnya kesadaran masyarakat untuk makanan dan minuman yang sehat seperti pada Tabel 1 . Dalam industri es krim di Indonesia terdapat tiga pemain besar yaitu Walls, Campina, dan Indoeskrim Meiji dimana Walls mendominasi pangsa pasar sebesar $50 \%$, diikuti oleh Campina 30\%, dan Indoeskrim Meiji 15\%.

Salah satu kunci sukses perusahaan dalam memenangkan persaingan pasar terletak pada proses penciptaan merek. Menurut Aaker (1997), perang pemasaran akan menjadi perang antar merek. Berbagai perusahaan dan investor akan mulai menyadari bahwa merek merupakan aset mereka yang terpenting, sehingga salah satunya cara untuk dapat menguasai pasar adalah memiliki pasar dengan merek yang dominan.

Tabel 1. Konsumsi es krim per kapita di Indonesia tahun 1999 dan 2004

\begin{tabular}{lccl}
\hline \multicolumn{1}{c}{ Konsumen } & $\begin{array}{c}\text { Konsumsi Es Krim per } \\
\text { Kapita (liter) }\end{array}$ & $\begin{array}{c}\text { Growth } \\
\mathbf{9 9 / 0 4}\end{array}$ & \multicolumn{1}{c}{ Sumber } \\
\hline Indonesia Tahun 1999 & 0,3 & $67 \%$ & Flavour house (2000) \\
Indonesia Tahun 2004 & 0,5 & & www.harianterbit.com (2004) \\
Eropa Tahun 2004 & 10 & & $\begin{array}{l}\text { www.harianterbit.com (2004) } \\
\text { Data Internal PT Indoeskrim } \\
\text { Pertumbuhan Dunia per Tahun } \rightarrow \text { 20\% }\end{array}$ \\
\hline
\end{tabular}


Cara yang paling kuat dalam memperoleh merek yang dominan adalah dengan iklan, terutama di televisi. Belanja iklan televisi yang dihabiskan oleh Walls hingga bulan Oktober 2006 adalah Rp 80 Milyar dan diikuti oleh Campina sebesar Rp 20 Milyar, sedangkan Indoeskrim Meiji hanya menghabiskan Rp 5 Milyar. Hal tersebut sebenarnya dapat menjadi alasan akan pangsa pasar yang diraih. Namun dengan terbatasnya kemampuan tiap perusahaan dengan adanya visi untuk menguatkan merek di pasar, maka bagi Indoeskrim Meiji yang memiliki jumlah belanja iklan terkecil ingin mencoba mengevaluasi bagaimanakah ekuitas merek Indoeskrim Meiji di pasar. Fakta di pasar, Indoeskrim Meiji menggunakan merek yang in line dengan merek-merek besar lainnya dalam satu holding (Salim Group) antara lain Indomie, Sambal Indofood, dan Susu Indomilk yang seharusnya dapat menguatkan ekuitas merek. Yoo et al. (2000) menyatakan bahwa ekuitas merek selain dibentuk oleh dimensi-dimensi ekuitas seperti kesadaran merek, asosiasi merek, kesan kualitas, dan loyalitas merek juga dibentuk oleh usaha-usaha pemasaran atau yang dikenal dengan antecendents dari ekuitas merek seperti harga, citra toko, intensitas distribusi, pengeluaran iklan dan potongan harga (Gambar 1). Menurutnya, usaha-usaha pemasaran yang dilakukan oleh perusahaan dapat meningkatkan atau bahkan mengurangi ekuitas merek. Oleh karenanya penelitian ini ingin menganalisis kontribusi yang diberikan oleh masingmasing dimensi ekuitas merek produkproduk tersebut yang meliputi brand awareness, brand perceived quality, brand association, dan brand loyalty terhadap ekuitas merek Indoeskrim Meiji. Penelitian ini dilakukan dengan membangun sebuah model hipotesis yang terdiri atas data variabel dimensi-dimensi ekuitas merek yang meliputi kesadaran merek dengan asosiasi merek yang kuat, kesan kualitas dan loyalitas merek, serta variabel-variabel usaha pemasaran yang diukur melalui persepsi responden terhadap harga, intensitas iklan, dan intensitas distribusi.

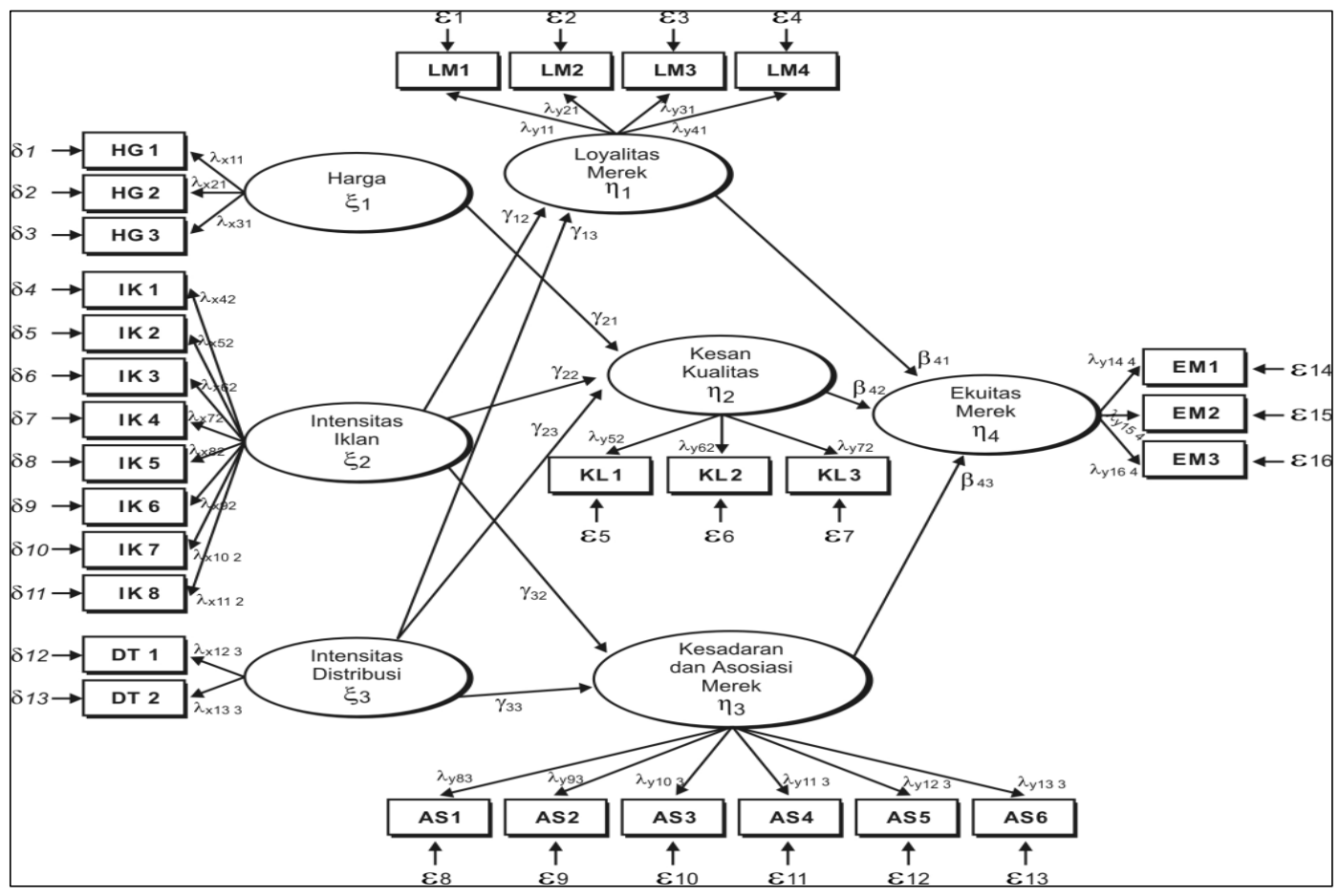

Gambar 1. Model Hipotetis Struktural Ekuitas Merek Indoeskrim Meiji (Model dimodifikasi dari Yoo et al. (2000)) 


\section{METODE}

\section{Desain, Lokasi, dan Waktu}

Penelitian ini dilakukan di pusat-pusat perbelanjaan di Kota Bogor, Jawa Barat pada bulan April hingga Mei 2006. Desain yang digunakan dalam penelitian ini yaitu cross-sectional study.

\section{Jumlah dan Teknik Penarikan Contoh}

Responden yang disertakan dalam penelitian ini berjumlah 150 orang. Teknik pengambilan contoh dalam penelitian ini adalah teknik non probability sampling. Pemilihan Kota Bogor dan pusat perbelanjaan non probability sampling (purposive), sedangkan penentuan responden dilakukan secara non probability sampling (convinience).

\section{Jenis Data, Cara Pengumpulan Data, dan Pengukuran}

Jenis dan sumber data berupa data primer dan sekunder. Data primer diperoleh dari hasil wawancara responden dengan menggunakan daftar pertanyaan terstruktur atau kuesioner. Responden yang ditemui adalah responden yang sedang melakukan aktivitas belanja di pusat perbelanjaan yang cukup ramai yaitu Ada Swalayan dan Hero, Ekalokasari Plaza, Ngesti Pajajaran, Ngesti Sukasari, Ramayana Pasar Bogor, Bogor Trade Mall, Warung Jambu, dan Yogya Cimanggu dengan pertimbangan jumlah responden yang bisa ditemui lebih banyak dan mewakili seluruh bagian Kota Bogor. Skala pengukuran yang digunakan adalah skala ordinal dimana skala ini mengurutkan data dari tingkat yang paling rendah ke tingkat yang paling tinggi atau sebaliknya dengan interval yang tidak harus sama.

Skala 1 = Sangat jelek, diberi bobot 1

Skala 2 = Jelek, diberi bobot 2

Skala $3=$ Cukup, diberi bobot 3

Skala $4=$ Baik, diberi bobot 4

Skala $5=$ Sangat baik, diberi bobot 5

\section{Analisis Data Variabel}

Structural Equation Model (SEM). Structural Equation Model (SEM) merupakan sekumpulan teknik statistika yang menjelaskan pengaruh dari dimensi-dimensi ekuitas merek serta usaha-usaha pemasaran dan memungkinkan suatu pengujian rangkaian hubungan yang relatif rumit secara simultan (Ferdinand 2005). Ferdinand (2005) juga menyebutkan indeks Goodness of Fit dari SEM yang dikembangkan seperti tersaji pada Tabel 2 .

Tabel 2. Indeks Goodness of Fit

\begin{tabular}{cc}
\hline Goodness of Fit Index & Cut-off-Value \\
\hline Chi-Square $\left(\mathrm{X}^{2}\right)$ & Diharapkan \\
kecil \\
Degree of Freedom $(\mathrm{df})$ & Positif \\
Significancy Probability $(P-$ & $\geq 0,05$ \\
value $)$ & \\
RMSEA & $\leq 0,08$ \\
GFI & $\geq 0,90$ \\
AGFI & $\geq 0,90$ \\
CFI & $\geq 0,95$
\end{tabular}

Sumber: Ferdinand (2005).

Tujuan SEM adalah menduga validitas suatu model yang berlandaskan suatu teori melalui pola ketergantungan dan saling ketergantungan ganda antara variabel bebas (eksogen) dan variabel terikat (endogen). SEM memiliki kemampuan dalam menganalisis faktor yang tak terukur (variabel laten) dan mampu memperhitungkan kesalahan pengukuran dalam proses pendugaan koefisien untuk meningkatkan ketepatan hasil dugaan (Suharjo 2004).

Terdapat tiga komponen pada model persamaan struktural, yaitu analisis lintas, konsep variabel laten dan model pengukuran serta penguraian pengaruh variabel laten. Pada diagram lintas dipresentasikan sebuah persamaan simultan. Salah satu keuntungan dari penggunaan diagram lintas adalah dapat menggambarkan hubungan antar variabel seperti yang dapat dilhat pada Gambar 2.

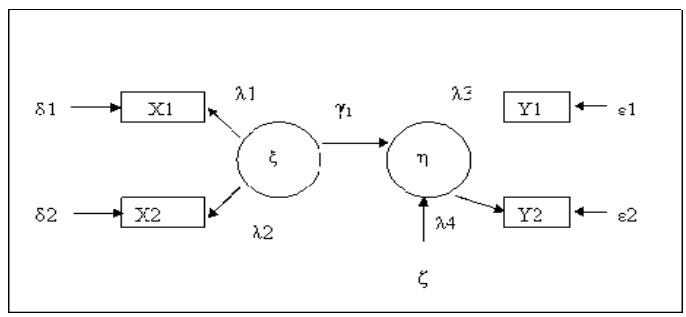

Gambar 2. Model Teoritis Diagram Lintas

Variabel laten digambarkan dengan simbol lingkaran sedangkan indikator digambarkan dengan simbol persegi. Tanda panah menggambarkan sebab akibat, dimana variabel pada pangkal panah mengakibatkan variabel pada ujung panah. $Y$ adalah koefisien pengaruh variabel laten bebas (eksogen) terhadap variabel laten tak bebas (endogen), sedangkan $\lambda$ adalah faktor muatan (loading factor). 
Pada penelitian ini variabel eksogen yang digunakan adalah harga ( $(1)$, intensitas iklan dan promosi (६2) serta intensitas distribusi (६3). Variabel eksogen ini digunakan untuk menduga konstruk endogen atau variabel tak bebas. Konstruk endogen atau variabel tak bebas dalam penelitian ini adalah kesadaran dan asosiasi merek (n1), kesan kualitas (n2), loyalitas merek (n3) dan ekuitas merek secara keseluruhan ( $n 4)$.

Variabel laten endogen kesadaran dan asosiasi merek (n3) diukur dengan membangkitkan variabel-variabel indikator AS1, AS2, AS3, AS4, AS5, dan AS6. Variabel laten endogen persepsi kualitas merek (n2) diukur dengan membangkitkan variabel indikator $\mathrm{KL} 1, \mathrm{KL} 2$, dan $\mathrm{KL} 3$. Variabel laten endogen loyalitas merek (n3) diukur dengan membangkitkan variabel indikator LM, LM2, LM3, LM4.

Variabel laten eksogen harga $(\xi 1)$ diukur dengan membangkitkan variabel indikator HGI, HG2, dan HG3. Variabel laten eksogen intensitas iklan dan promosi (६2) diukur dengan membangkitkan IK1, IK2, IK3, IK4, IK5, IK6, IK7, dan IK8. Sementara itu, untuk variabel laten eksogen intensitas distribusi (६3) diukur dengan membangkitkan variabel indikator DT1 dan DT2.

Dalam penelitian ini dihipotesiskan adanya pengaruh dari variabel laten eksogen berupa variabel harga ( $(1)$, variabel intensitas iklan dan promosi (६2), dan variabel intensitas distribusi (§3) terhadap variabel laten endogen kesadaran dan asosiasi merek (n1), variabel persepsi kualitas merek (n2), variabel persepsi loyalitas merek (n3) dalam membentuk ekuitas merek secara keseluruhan (n4). Daftar variabel dan instrumen penelitian disajikan pada Tabel 3.

Selanjutnya analisis SEM dilakukan untuk menganalisa model tersebut dan besarnya konstribusi yang diberikan untuk tiap-tiap indikator, maka dilakukan analisis SEM dengan menggunakan software Linier Structural Relationship (LISREL 8.51).

Tabel 3. Variabel dan Instrumen Penelitian

\begin{tabular}{|c|c|c|}
\hline ELEMEN/DIM & NSI & HARGA \\
\hline \multirow{14}{*}{$\begin{array}{c}\text { Bauran } \\
\text { Pemasaran }\end{array}$} & HG1 & Harga Indoeskrim Meiji Mahal \\
\hline & HG2 & Harga Indoeskrim Meiji Murah \\
\hline & HG3 & Harga Indoeskrim Meiji sudah tepat \\
\hline & & INTENSITAS IKLAN DAN PROMOSI \\
\hline & IK1 & Iklan Indoeskrim Meiji relatif lebih banyak dibandingkan dengan es krim lain \\
\hline & IK2 & Saya sering melihat iklan Indoeskrim di televisi \\
\hline & IK3 & Saya sering melihati iklan Indoeskrim meiji di media cetak \\
\hline & IK4 & Saya sering mendengar iklan Indoeskrim Meiji di radio \\
\hline & IK5 & Indoeskrim Meiji melakukan kegiatan pemasaran selain iklan secara gencar \\
\hline & IK6 & Indoeskrim memberi sampel gratis \\
\hline & IK7 & Indoeskrim sering melakukan promosi dg menjadi sponsor kegiatan tertentu \\
\hline & IK8 & Indoeskrim meiji sering mengadakan event/kegiatan yang menarik \\
\hline & & INTENSITAS DISTRIBUSI \\
\hline & $\begin{array}{l}\text { ID1 } \\
\text { ID2 }\end{array}$ & $\begin{array}{l}\text { Indoeksrim Meiji dijual pada banyak toko/warung/supermarket/asongan dll } \\
\text { Indoeskrim Meiji selalu tersedia di setiap toko/warung/supermarket }\end{array}$ \\
\hline \multirow{15}{*}{ Ekuitas Merek } & & KESADARAN DAN ASOSIASI MEREK \\
\hline & AM1 & Indoeskrim Meiji memiliki kesan yang positif \\
\hline & AM2 & Saya merasa tidak asing dengan Indoeskrim Meiji \\
\hline & AM3 & $\begin{array}{l}\text { Saya memiliki kesulitan untuk membayangkan Indoeskrim Meiji dalam ingatan } \\
\text { saya }\end{array}$ \\
\hline & AM4 & Saya dapat membedakan Indoeskrim Meiji dengan jenis es krim lainnya \\
\hline & AM5 & Saya dapat dengan cepat membayangkan simbol atau logo Indoeskrim Meiji \\
\hline & AM6 & $\begin{array}{l}\text { Karakteristik lain dari Indoeskrim Meiji (selain logo) dapat dengan cepat saya } \\
\text { bayangkan dalam ingatan saya }\end{array}$ \\
\hline & \multicolumn{2}{|r|}{ KESAN KUALITAS } \\
\hline & KU1 & Indoeskrim Meiji berkualitas tinggi \\
\hline & KU2 & Saya yakin Indoeskrim Meiji disukai oleh keluarga/teman saya \\
\hline & KU3 & Rasa Indoeskrim Meiji sangat saya sukai \\
\hline & \multicolumn{2}{|r|}{ LOYALITAS MEREK } \\
\hline & LM1 & Saya sedang memikirkan untuk menjadi konsumen setia Indoeskrim Meiji \\
\hline & LM2 & Saya akan tetap mengkonsumsi Indoeskrim Meiji di masa mendatang \\
\hline & LM3 & $\begin{array}{l}\text { Saya tidak akan membeli merek lain jika Indoeskrim Meiji tersedia di } \\
\text { toko/warung/supermarket yang saya kunjungi }\end{array}$ \\
\hline
\end{tabular}


LM4 Saya akan merekomendasikan kawan/saudara untuk membeli Indoeskrim Meiji

\begin{tabular}{cl}
\hline & \multicolumn{1}{c}{ EKUITAS MEREK KESELURUHAN } \\
\hline EM1 & $\begin{array}{l}\text { Jika ada merek es krim lain yang memiliki kualitas sebaik Indoeskrim Meiji, saya } \\
\text { lebih memilih membeli Indoeskrim }\end{array}$ \\
EM2 & $\begin{array}{l}\text { Jika ada merek es krim lain yang memiliki karakteristik yang hampir sama } \\
\text { dengan Indoeskrim Meiji, saya lebih memilih untuk membeli Indoeskrim Meiji }\end{array}$ \\
EM3 & $\begin{array}{l}\text { Jika ada merek Es Krim yang menawarkan harga yang lebih murah dibandingkan } \\
\text { Indoeskrim Meiji, saya lebih memilih unuk membeli Indoeskrim Meiji }\end{array}$
\end{tabular}

\section{HASIL DAN PEMBAHASAN}

Dari hasil penelitian terhadap 150 orang responden didapatkan mayoritas responden adalah wanita berusia 31-40 tahun, menikah, memiliki anak lebih dari 2 orang, sarjana S1, ibu rumah tangga, pekerjaan pasangan/ suami adalah middle up management, dan memiliki pengeluaran rumah tangga antara Rp 800.000,00 sampai Rp 1.250.000,00.

Hasil analisis Structural Equation Modeling (SEM) menunjukkan bahwa model hipotesis atau model teori sudah mampu menjelaskan fakta empiris yang ada di lapangan walaupun masih ada variabel yang memiliki nilai faktor muatan $<1,96$. Namun, model tersebut merupakan model yang paling optimal. Ekuitas merek Indoeskrim Meiji dibentuk oleh tiga dimensi yaitu loyalitas merek, perceived quality, dan asosiasi merek. Dimensi asosiasi merek merupakan penggabungan dari dimensi asosiasi merek dan kesadaran merek karena memiliki karakteristik yang hampir sama. Dimensi loyalitas merek memiliki kontribusi yang positif dan signifikan terhadap ekuitas merek Indoeskrim Meiji. Begitu juga dengan dimensi asosiasi merek, sedangkan dimensi kualitas merek memiliki kontribusi yang positif namun tidak signifikan.

Dari hasil uji kecocokan model yang dapat dilihat pada Tabel 4 diperoleh hasil bahwa secara keseluruhan model dapat diterima. Hal tersebut pertama-tama dapat dilihat dari nilai Root Mean Square Error of Approximation (RMSEA) sebesar 0,043 yang lebih kecil dari 0,08. Nilai Goodness of Fit Index juga menunjukkan nilai yang cukup tinggi yaitu 0,84. Untuk Comparative Fit Index (CFI) uji kecocokan model menunjukkan nilai 0,97 yang mengindikasikan tingkat fit yang tinggi karena hampir mendekati 1 . Nilai Chi Square yang dilihat disini adalah nilai Chi square relatif yaitu Chi Square Relatif (X2 relatif) terhadap Degree of Freedom (df) dan nilainya kurang dari 2 yaitu 1,27. Hal tersebut menunjukkan bahwa model dapat diterima (acceptable fit).

Pada Gambar 3 terlihat bahwa variabelvariabel indikator yang digunakan untuk mengukur variabel laten endogen loyalitas merek, kesan kualitas, kesadaran dan asosiasi merek serta ekuitas merek dan variabel laten eksogen harga, intensitas iklan dan intensitas distribusi menunjukkan hasil yang signifikan. Hal ini diindikasikan dengan nilai koefisien $\lambda$ (lambda) yang lebih besar dari 1,96 sehingga dengan demikian variabel-variabel indikator yang digunakan untuk mengukur variabel laten tersebut telah valid dan reliabel.

Secara keseluruhan ekuitas merek (overall brand equity) Indoeskrim Meiji dibentuk oleh variabel Loyalitas Merek dengan nilai $\beta$ sebesar 0,39 , lebih tinggi dari variabel Asosiasi Merek yang memiliki nilai $\beta$ sebesar 0,24. Hal tersebut menunjukkan bahwa loyalitas merek adalah variabel yang sangat mempengaruhi ekuitas merek dari Indoeskrim Meiji. Hal tersebut sebenarnya sudah dapat dijelaskan secara struktural karena tidak ada penambahan jalur keterhubungan dalam model. Nilai $\beta$ dan nilai-t ekuitas merek dengan dimensi-dimensi equitas merek dapat dilihat pada Tabel 5.

Tabel 4. Hasil uji kecocokan model

\begin{tabular}{lccc}
\hline \multicolumn{1}{c}{ Ukuran Kecocokan Model } & Hasil Perhitungan & $\begin{array}{c}\text { Kriteria } \\
\text { Penerimaan }\end{array}$ & Kriteria Uji \\
\hline Chi Square (X2) & 408,22 & Diharapkan kecil \\
Degree of Freedom (df) & 321,00 & $<2-3$ & Acceptable Fit \\
X2 Relatif & 1,27 & 0,06 & Good Fit \\
Root Mean Square Error of & 0,043 & $0-1$ & Good Fit \\
$\quad$ Approximation (RMSEA) & 0,84 & $>0,95$ & Good Fit \\
Goodness of Fit Index (GFI) & 0,97 & & \\
Comparative Fit Index (CFI)
\end{tabular}


Tabel 5. Faktor muatan $\beta$ (Beta) dan nilai-t dalam hubungan ekuitas merek dengan dimensi-dimensi ekuitas merek

\begin{tabular}{lcr}
\hline $\begin{array}{c}\text { Dimensi Ekuitas } \\
\text { Merek }\end{array}$ & $\begin{array}{c}\text { Faktor } \\
\text { Muatan } \\
\text { ( } \boldsymbol{\beta} \text { atau B) }\end{array}$ & Nilai-t \\
\hline Loyalitas Merek & 0,39 & 4,81 \\
Asosiasi Merek & 0,24 & 2,83 \\
Kualitas Merek & 0,07 & $-0,88$ \\
\hline
\end{tabular}

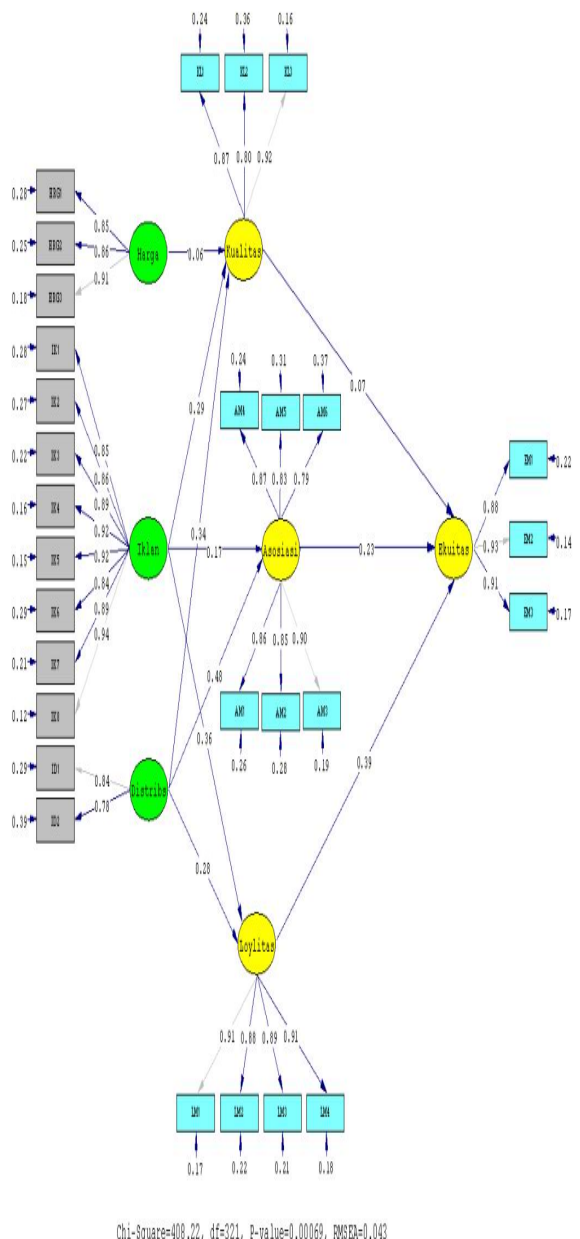

Gambar 3. Hasil perhitungan Lisrel Standardized Solution

Dengan memperhatikan nilai faktor muatan, terlihat bahwa dimensi loyalitas merek memiliki kontribusi yang paling besar terhadap pembentukkan ekuitas merek dibandingkan dengan dimensi asosiasi dan kualitas merek. Hal ini menunjukkan bahwa dalam kasus ini ekuitas merek Indoeskrim
Meiji paling utama dibentuk oleh dimensi loyalitas merek. Meskipun ekuitas merek Indoeskrim Meiji sebenarnya masih rendah apabila dilihat dari jawaban responden yang mayoritas netral. Namun terdapat dimensi ekuitas merek yang paling berpotensi untuk dikembangkan yaitu loyalitas merek

Hubungan antara dimensi-dimensi ekuitas merek dengan usaha-usaha pemasaran ditunjukkan dengan nilai koefisien lintas y (gamma). Hasil estimasi faktor muatan y (gamma) dan nilai-t dalam hubungan dimensi-dimensi ekuitas merek dengan usaha-usaha pemasaran dapat dilihat pada Tabel 6.

Tabel 6. Faktor muatan y (Gamma) dan nilai-t dalam hubungan dimensi-dimensi ekuitas merek dengan usaha-usaha pemasaran

\begin{tabular}{|c|c|c|c|}
\hline $\begin{array}{l}\text { Dimensi } \\
\text { Ekuitas } \\
\text { Merek }\end{array}$ & $\begin{array}{c}\text { Usaha- } \\
\text { Usaha } \\
\text { Pemasaran }\end{array}$ & $\begin{array}{l}\text { Faktor } \\
\text { Muatan } \\
\text { (Y atau } \\
\text { Gamma) }\end{array}$ & Nilai-t \\
\hline \multirow{2}{*}{$\begin{array}{c}\text { Loyalitas } \\
\text { Merek }\end{array}$} & $\begin{array}{l}\text { Intensitas } \\
\text { distribusi }\end{array}$ & 0,30 & 3,08 \\
\hline & $\begin{array}{l}\text { Intensitas } \\
\text { iklan \& } \\
\text { promosi }\end{array}$ & 0,36 & 4,29 \\
\hline \multirow{2}{*}{$\begin{array}{c}\text { Asosiasi } \\
\text { Merek }\end{array}$} & $\begin{array}{l}\text { Intensitas } \\
\text { distribusi }\end{array}$ & 0,50 & 4,91 \\
\hline & $\begin{array}{l}\text { Intensitas } \\
\text { iklan \& } \\
\text { promosi }\end{array}$ & 0,16 & 2,01 \\
\hline \multirow{3}{*}{$\begin{array}{l}\text { Kualitas } \\
\text { Merek }\end{array}$} & Harga & 0,06 & $-0,65$ \\
\hline & $\begin{array}{l}\text { Intensitas } \\
\text { distribusi }\end{array}$ & 0,37 & 3,48 \\
\hline & $\begin{array}{l}\text { Intensitas } \\
\text { iklan \& } \\
\text { promosi }\end{array}$ & 0,29 & 3,27 \\
\hline
\end{tabular}

Tabel 6 menunjukkan bahwa usahausaha pemasaran yang dipersepsikan dalam bentuk harga mempunyai kontribusi yang positif namun tidak signifikan dalam hubungan harga terhadap kualitas merek, hal tersebut ditunjukkan dengan nilai faktor muatan sebesar 0,06 namun memiliki nilai $t$ value negatif sebesar 0,65 . Usaha-usaha pemasaran yang dipersepsikan dalam bentuk intensitas iklan memiliki kontribusi yang positif dan signifikan dalam hubungannya dengan dimensi loyalitas merek, asosiasi merek, dan kualitas merek. Usaha-usaha pemasaran yang dipersepsikan dalam bentuk intensitas distribusi memiliki kontribusi yang paling besar terhadap pembentukan dimensi asosiasi merek dan kualitas merek. Begitu pun dimensi loyalitas 
merek yang memiliki kontribusi terbesar dalam pembentukkan ekuitas merek Indoeskrim Meiji juga didukung oleh usaha pemasaran dalam bentuk intensitas distribusi dengan nilai sedikit lebih rendah dari intensitas iklan dan promosi. Intensitas iklan dan promosi memiliki kontribusi yang paling utama terhadap pembentukan dimensi loyalitas merek. Responden mempersepsikan bahwa event-event/kegiatan akan berdampak pada loyalitas merek sehingga akan meningkatkan ekuitas merek Indoeskrim Meiji.

Dimensi kesan kualitas merek memiliki kontribusi terendah dan bentuk hubungan yang negatif terhadap ekuitas merek. Hal tersebut dipengaruhi oleh variabel harga yang memiliki kontribusi terendah terhadap kesan kualitas merek. Harga yang tinggi pada produk es krim ternyata akan membuat kesan kualitas yang negatif terhadap produk tersebut. Hal tersebut menunjukkan bahwa harga yang tinggi belum tentu dikaitkan dengan produk yang mempunyai kesan kualitas yang baik. Harga yang terlalu tinggi bahkan menjadikan kesan kualitas secara keseluruhan akan negatif dan bahkan menurunkan ekuitas merek.

\section{Implikasi Manajerial}

Pihak Indoeskrim Meiji harus cermat dalam mengelola konsumen yang loyal dengan cara memperlakukan konsumen dengan layak, menjalin hubungan yang dekat dengan pelanggan, mengukur atau mengelola kepuasan pelanggan, menciptakan biaya peralihan, dan memberikan ekstra produk (souvenir, penjelasan produk, atau sampel). Apabila hal ini dilakukan dengan baik maka hasilnya bukan saja dapat mempertahankan konsumen loyal yang sudah ada namun juga dapat mengakuisisi konsumen yang tidak loyal menjadi konsumen yang loyal. Aspek promosi berkaitan dengan upaya perusahaan untuk mengkomunikasikan nilai yang ditawarkan kepada konsumen tentang keberadaan perusahaan beserta produknya, mempertahankan loyalitas dan minat atas produk yang dipasarkan. Dalam hal ini, loyalitas konsumen yang sudah ada terhadap Indoeskrim Meiji akan dapat terjaga selama perusahaan secara intensif mengadakan event-event yang tentunya dapat meningkatkan ekuitas merek. Harga yang tinggi pada produk es krim ternyata akan membuat kesan kualitas yang negatif terhadap produk tersebut. Konsumen akan dengan cepat menghilangkan suatu brand dari benak mereka apabila harganya terlalu mahal sehingga ekuitas merek terhadap brand tersebut rendah. Hal tersebut menunjukkan bahwa harga yang tinggi belum tentu dikaitkan dengan produk yang mempunyai kesan kualitas yang baik. Harga yang terlalu tinggi bahkan menjadikan kesan kualitas secara keseluruhan akan negatif dan bahkan menurunkan ekuitas merek. Sebagai contoh Haagen Daaz dan Baskin Robbins jauh di atas harga Walls dan Campina dimana untuk ukuran 1 liter saja bisa mencapai Rp 100.000,00 sehingga harga yang tinggi tersebut dapat membuat kesan kualitas secara keseluruhan terhadap merek tersebut negatif atau berbanding terbalik. Perbedaan harga tersebut menggambarkan bahwa kedua merek produk diperuntukkan bagi dua segmen konsumen yang berbeda.

\section{KESIMPULAN DAN SARAN}

\section{Kesimpulan}

Dimensi kesan kualitas merek memiliki kontribusi terendah dan bentuk hubungan yang negatif terhadap ekuitas merek. Hal tersebut dipengaruhi oleh variabel harga yang memiliki kontribusi terendah terhadap kualitas merek. Harga yang tinggi pada produk es krim ternyata akan membuat kesan kualitas yang negatif terhadap produk tersebut. Hal tersebut menunjukkan bahwa harga yang tinggi belum tentu dikaitkan dengan produk yang mempunyai kesan kualitas yang baik. Harga yang terlalu tinggi bahkan menjadikan kesan kualitas secara keseluruhan akan negatif dan bahkan menurunkan ekuitas merek.

\section{Saran}

1. Indoeskrim Meiji mungkin dapat mentargetkan pada konsumenkonsumen yang sudah loyal akan Indomie, Indomilk atau sambal Indofood dengan cara consumer promo. Sebagai contoh, apabila membeli produk-produk Indofood berhadiah Indoeskrim Meiji atau join promo dengan event-event yang diadakan oleh produk-produk Indofood

2. Berdasarkan hasil penelitian, direkomendasikan kepada produsen Indoeskrim Meiji untuk berhati-hati apabila ingin menciptakan produk premium dari segi harga jangan terlalu tinggi atau jauh dari range atau market leader price yang ada, 
3. Agar terlihat lebih in line dengan produk lainnya, Indoeskrim Meiji dapat melepas nama Meiji-nya, sehingga cukup Indoeskrim saja.

\section{DAFTAR PUSTAKA}

Aaker DA. 1997. Manajemen Ekuitas Merek: Memanfaatkan Nilai dari Suatu Merek. Jakarta: Penerbit Mitra Utama.

Indoeskrim Meiji. 2005. Data Internal Indoeskrim Meiji. (Tidak dipublikasikan)
Ferdinand A. 2005. Structural Equation Modeling dalam Penelitian Manajemen. Fakultas Ekonomi. Universitas Diponegoro.

Suharjo, Budi. 2004. Modul Kuliah yang tidak dipublikasikan.

Yoo B, N Donthu, dan S Lee. 2000. An Examination Of Selected Marketing Mix Elements and Brand Equity. Journal of The Academy of Marketing Science, 28 (2), Academy of Marketing Science.

\footnotetext{
* Korespondensi:

Telp : +62-2518628303

Email : sumarwan@mb.ipb.ac.id
} 